\title{
Examination of the Thermal Neutrality for Residents of a Warm-Humid Urban Environment
}

\author{
Adewale Oluseyi Adunola \\ Department of Architecture, University of Johannesburg, South Africa \\ Department of Architecture, Obafemi Awolowo University, Ile-Ife, Nigeria \\ Tel: 27-623-403-707Ｅ-mail: adewalea@uj.ac.za,wadunola@yahoo.com
}

Received: July 21, 2016 Accepted: September 6, 2016

doi:10.5296/emsd.v5i2.9760 URL: http://dx.doi.org/10.5296/emsd.v5i2.9760

\begin{abstract}
The paper examined the applicability of thermal neutrality equations to the thermal responses of residents in a field study within a tropical warm-humid urban environment in Ibadan, Nigeria. A total of 528 houses were selected for the survey using systematic random sampling within twelve neighborhoods selected by stratified random sampling in the metropolis. For each selected building, an adult resident filled a questionnaire indicating the adaptive thermal response at different periods of the day using the ASHRAE thermal comfort scale. Measurement of indoor and outdoor air temperature and other thermal comfort parameters was done in representative buildings in the neighborhoods. It was found that the residents' thermal neutrality was higher than values predicted by applied thermal neutrality equations inferring opportunities for sustainable comfort. It was concluded that there is essentially a climatic and contextual basis for the application of thermal neutrality equations.
\end{abstract}

Keywords: Adaptive response, Air temperature, Indoor comfort, Sustainability, Thermal neutrality, Urban microclimate, Warm-humid environment

\section{Introduction}

The high levels of air temperature in tropical climates affect the indoor comfort of urban residents. City microclimate and indoor comfort are of concern due to the high rate of urbanization and the attendant growth in urban population and urban housing demand. Thermal Comfort is generally defined as that condition of mind which expresses satisfaction with the thermal environment (ISO1984). It is a state of well-being with respect to temperature depending on achieving a balance between the heat being produced by the body and the loss of heat to the surroundings. There is a particular neutrality temperature that is relevant to a specific comfort situation. The neutrality temperature also called thermal 
neutrality is the optimum temperature when people feel neither warm nor cool but neutral (Humphreys 1976). To optimize thermal comfort inside a naturally ventilated room, the interior temperature should be maintained at or close to the neutrality temperature.

A number of thermal neutrality equations have been formulated based on previous research in other regions. It will be of relevance to look into the comfort level of the residents of a city in the warm-humid tropical climatic environment and determine the neutrality temperature because of the peculiar challenges of such a region. Such a study will enhance our understanding of the requirements of indoor comfort in the local context with respect to temperature and aid the development of acceptable local building standards. This study therefore looks into the thermal neutrality of residents of a warm-humid city in Nigeria and examines the applicability of thermal neutrality equations to the result of the survey. The relevance of this study is that it compares theory of thermal comfort to empirical results in the context of the warm-humid climate. Specifically it looks into the determination of thermal neutrality in a warm-humid city comparing the obtained field study result to predictions from theoretical models. It should be noted that for the warm-humid climate, sustainability in the urban built environment can be enhanced with the attainment of higher values of thermal neutrality.

\section{Literature Review}

The parameters contributing to thermal comfort have been established to be air temperature, mean radiant temperature, air velocity and relative humidity which are environmental elements as well as clothing and metabolism level which are personal parameters (Fanger 1973, Givoni 1976, Markus and Morris 1980). The two initial concepts forming the basis of the study of thermal comfort from literature are the physiological and the psychological concepts. The physiological theory lays the foundation for relating the physical parameters of an environment to the thermal state of the body. The bodily exposure to the thermal environment translates into feelings based on the physiological reactions. The human subjective psychology gives an insight into the human experience of thermal comfort. The relevance of the psychological approach to thermal comfort is shown in literature to be evident in the need to decipher the different degrees of comfort and discomfort responses to different thermal conditions. The psychological models of thermal comfort have been developed based on two approaches: the prompted vote and the behavioral approach as developed by Fanger (1973) and McIntyre (1980) with a comfort equation. The physiological approach has become more relevant in the assessment of stress conditions.

The concept of adaptive thermal comfort is established in literature as the basis of the thermal experience in an urban spatial environment (Baker and Standeven 1994, deDear 1998, Merghani 2004). The adaptive principle states that "if a change occur in the thermal environment which tends to produce discomfort, people will respond in ways that tend to restore their comfort" (Humphreys and Nicol 2002, Santamouris 2006, Humphreys et al 2007). The adaptive opportunity create an entirely diversified range of thermal response which have been found to be more extended than the normal influence of the fundamental thermal comfort parameters. The neutrality temperature may thus be affected by the adaptive 
comfort principle. There are therefore additional parameters to be analyzed on a contextual platform using the field study approach for proper understanding of the dynamics of sustainable thermal comfort.

The concept of bioclimatic design has made the study of thermal comfort more incorporated in the practice of architecture. The architectural design of a building is traditionally shaped by the challenges and opportunities of the regional climate. The analysis of the local climatic conditions is the starting point in formulating building and urban design principles aimed at maximizing comfort and minimizing the use of energy for heating and cooling. Architecture intentionally modifies the climate of an immediate area. Different comfort standards are justified for countries with different climatic conditions and stages of economic development. According to Givoni (1998), studies have indicated that persons living in hot countries prefer higher temperatures than the recommendations by the American and European standards such as ASHRAE comfort nomogram and Fanger's Comfort Equation. Fanger (1970) defines comfort as the conditions under which the subjective thermal comfort votes are between 'slightly cool' and 'slightly warm' on a seven-point thermal comfort scale. According to Givoni, the problem with Fanger's heat balance equation is that the effect of air speed is taken into account only with respect to the convective heat exchange, while its effect on sweat evaporation is not included in the heat balance formula. At a given warm temperature and humidity, when the convective heat exchange is rather small, the PMV will have almost the same value at different speeds. This limits the evaluative capacity of Fanger's formula on sensory effect of air speed which is very significant in hot-humid climates (Givoni 1998).

Acclimatization to the local climate was reported in Colima, Mexico, a warm-humid town. The minimum temperatures from June to October (raining season) would be considered uncomfortable by ASHRAE comfort zone suggesting the need for air-conditioning. Residents however felt comfortable without using air-conditioning, reflecting acclimatization to the local climate (Givoni 1998). According to Mallick (1996), the perception of comfort in the warm-humid climate is influenced by long-term conditioning of high temperature and humidity. The exterior conditions influence clothing, personal habits and expectations of comfort. In the study of occupants of urban housing in Bangladesh, it was found that there was unexpected tolerance to high temperatures and very high humidity for comfort (Mallick 1996). The adaptive tolerances can ultimately bring about sustainable thermal comfort within the buildings

Climatic condition was considered from the findings of Haase and Amato (2009) as the most important factor in the determination of thermal comfort. The different hourly weather data were analyzed with the help of dynamic computer simulations. The study determined the potential for natural ventilation in achieving thermal comfort. In tropical climates the improvement in comfort by natural ventilation ranged between $9 \%$ and $41 \%$. For subtropical climate the improvement varied between $3 \%$ and 14\%. In the temperate climate, the improvements varied between $8 \%$ and $56 \%$. The study showed that natural ventilation has a good potential in tropical and temperate climates but not in subtropical climates. The derivation of an equation for thermal comfort in free-running buildings established a relationship between indoor comfort and outdoor climate (Nicol and Humphreys 2010). The 
paper describes how the indoor comfort conditions were related to the running mean of the outdoor temperature, and addressed the effect of air movement and humidity. The dependence of indoor environmental conditions on the external climatic condition is emphasized by the paper.

The studies in different locations have been contextualized because of the use of different groups of people and different physical environments. It has been shown by Humphreys (1978) and Auliciems $(1981,1982)$ that thermal neutrality is a function of the prevailing climate. It follows that findings based on studies in the temperate climate cannot be generally applicable to the tropical climate. Many of the developed indices have limitations with respect to high temperature and high relative humidity. According to Markus and Morris (1980), Sharma and Ali (1986) and Ogunsote and Prucnal-Ogunsote (2002), none of the indices appears to be universally satisfactory over the entire range of environmental conditions.

Noted by Humphreys (1976) are also the discrepancies between the predictions of the theoretical models and the observations of field study. The discrepancies indicate the areas where the understanding of the subject is incomplete. The conclusion from literature is that there is requirement for the validation of the theoretical models through field studies. Peeters et al (2009) specifically stressed the need for the field study approach to discover real situations in residential buildings. There are a number of equations developed from previous works for obtaining neutrality temperature $T_{n}$. These will be applied in this study to make comparisons with the result of neutrality temperature determined for the field study. According to Humphreys (1978), $\mathrm{T}_{\mathrm{n}}=11.9+0.534 \mathrm{~T}_{\text {oav }}$ where $\mathrm{T}_{\mathrm{oav}}$ is the month's mean outdoor temperature. Auliciems (1981) gave the equation $\mathrm{T}_{\mathrm{n}}=17.6+0.31 \mathrm{~T}_{\text {oav }}$ while Griffiths (1990) provided the equation: $\mathrm{T}_{\mathrm{n}}=12.1+0.534 \mathrm{~T}_{\text {oav }}$. Also, Nicol and Roaf (1996) deduced the equation: $T_{n}=17+0.38 T_{\text {oav }}$, while the deDear et al (1997) equation is $T_{n}=17.8+0.31$ $\mathrm{T}_{\text {oav }}$.

\section{Study Area}

Ibadan metropolis is an urban centre located on latitude $7^{\circ} 23^{\prime} \mathrm{N}$ and longitude $3^{\circ} 55^{\prime} \mathrm{E}$ in the South-Western part of Nigeria. The city ranges in elevation from $150 \mathrm{~m}$ above sea level in the valley area to $275 \mathrm{~m}$ on the major north-south ridge which crosses the central part of the city (http://www.absoluteastronomy.com/topics/Ibadan). Figure 1 shows the distribution of the residential building densities in the metropolis. Ibadan falls within the warm-humid tropical climate with a seasonally humid classification because of its inland location. The climatic pattern is dominated by periods of high rainfall especially in the rainy season. There are considerable solar radiation intensity and high temperatures, high humidity, light winds and long periods of still air. There are two broad seasonal patterns in Ibadan, namely the dry season (November to April) and the rainy season (May to October). The weather conditions in Ibadan, as well as in other places in Nigeria and other West African countries during the course of a given year actually depends on the location of the place in relation to the fluctuating surface position of the Inter-Tropical Discontinuity (ITD) in the region (Ojo, 1977). 


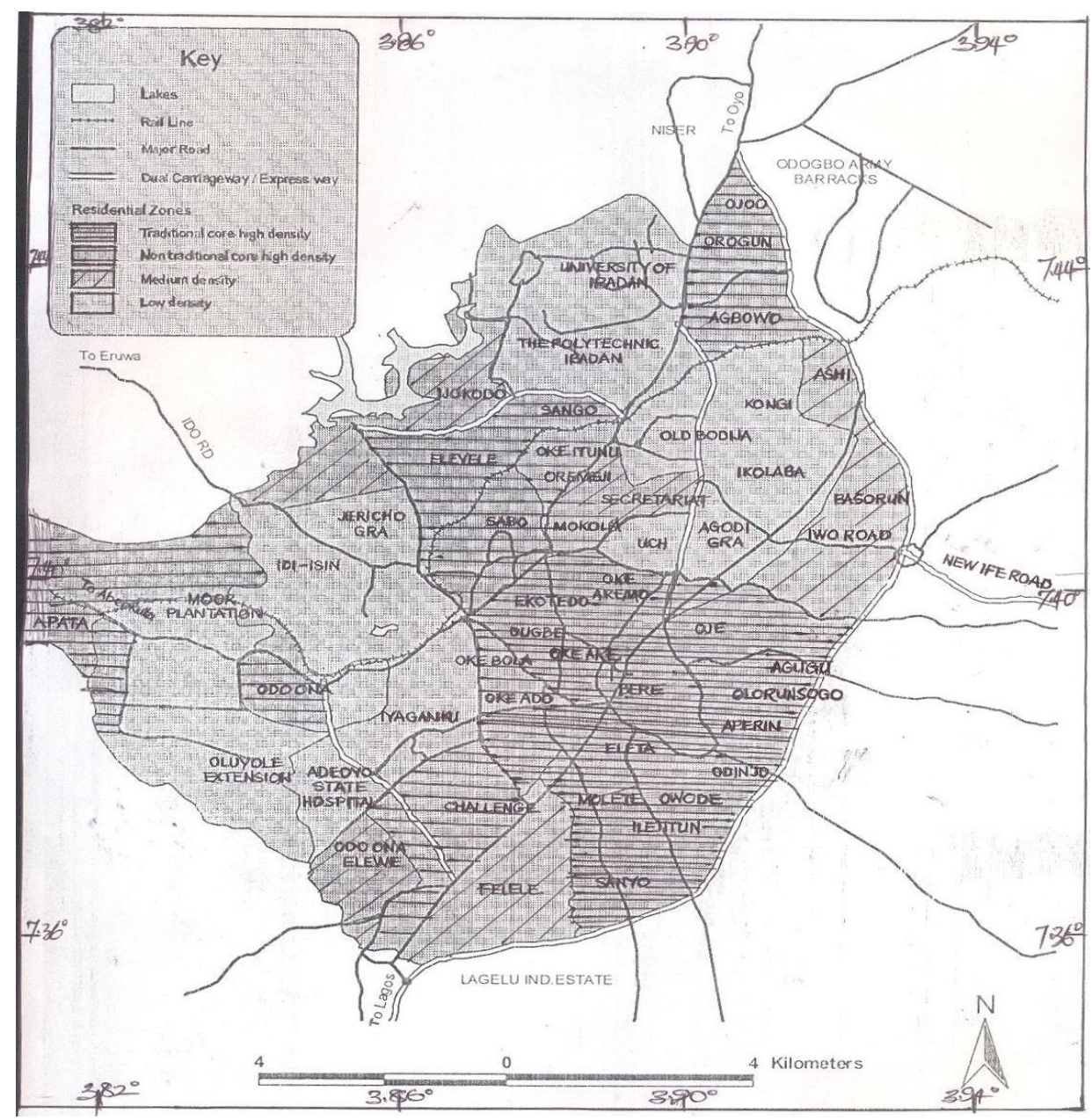

Figure 1. Ibadan metropolis showing the building densities.

Source: Adapted from Asiyanbola (2011).

According to the analysis of the Ibadan climate given by $\mathrm{BBC}$ Weather (http://en.wikipeadia.org/wiki/Ibadan,Nigeria\#\#), the record highest temperatures of $39^{\circ} \mathrm{C}$ occurred in February and $38^{\circ} \mathrm{C}$ in March and April. The mean maximum temperature was highest in February and March $\left(34^{\circ} \mathrm{C}\right)$ closely followed by April, January and November $\left(33^{\circ} \mathrm{C}\right)$. The months with the lowest mean maximum temperatures were August $\left(27^{\circ} \mathrm{C}\right)$ and July $\left(28^{\circ} \mathrm{C}\right)$. The record lowest temperature was $10^{\circ} \mathrm{C}$ in January. The mean minimum temperature was least in January, July, August and December $\left(21^{\circ} \mathrm{C}\right)$ and was highest in March and April $\left(23^{\circ} \mathrm{C}\right)$. With respect to the sunshine hours, highest value of 198 was in February, November and December followed by 170 in January, April and May. From the analysis, the month of April in which the survey was done rightly qualified as one of the expected hot and uncomfortable months in the study area.

\section{Methodology}

A thermal comfort field-survey was conducted in Ibadan metropolis. Ten percent (12) of the 


\section{Macrothink}

119 neighborhoods identified from the metropolitan map were selected by stratified random sampling comprising 2 low, 3 medium and 7 high residential densities. The total number of houses in each of the neighborhoods was estimated to be an average value of 885 based on data from NBS (2008). A sample size of five percent of this gave 44 houses in each neighborhood which were selected using systematic random sampling to give a total of 528 houses for the survey. For each selected building, an adult member of a household was sampled for questionnaire administration. Indoor thermal comfort assessment was done by the respondents using the ASHRAE thermal sensation scale. They also provided information on their clothing, activity level and relevant physical/personal characteristics as well as any adaptive action taken. The respondents that were literate filled the questionnaire independently as they monitored their thermal feelings during the day but about $15 \%$ of respondents with lower literacy level were interviewed to complete the questionnaire from memory. The rating of thermal response ranged from -3 through 0 to +3 as indicated in Table 1 . It was the mean comfort vote that was utilized in the analysis. The mean comfort vote was calculated using the following computation:

Mean Comfort Vote $=\Sigma$ (Thermal response rating $\mathrm{x}$ Number of votes $) \div$ Total number of respondents.

The measurements of relevant climatic parameters such as air temperature, air velocity, relative humidity were done in representative buildings in the neighborhoods. The weather-measuring instruments used comprised the following: La Crosse Technology Instant Transmission Plus Weather Stations which offered immediate update of all outdoor and indoor climatic data measured from transmitters (with the indoor temperature rangeof $-9.9^{\circ} \mathrm{C}$ to $+59.9{ }^{\circ} \mathrm{C}$ with $0.1{ }^{\circ} \mathrm{C}$ resolution and $+/-1{ }^{\circ} \mathrm{C}$ accuracy, outdoor temperature range of $-39.9{ }^{\circ} \mathrm{C}$ to $59.9^{\circ} \mathrm{C}$ with $0.1{ }^{\circ} \mathrm{C}$ resolution and $+/-1{ }^{\circ} \mathrm{C}$ accuracy and humidity range of $1 \%$ to $99 \%$ with $1 \%$ resolution and $\pm 5 \%$ accuracy); Smart Sensor Intell Plus Electronic Anemometers (with wind speed range of 0 to $30 \mathrm{~m} / \mathrm{s}, 0.1 \mathrm{~m} / \mathrm{s}$ resolution and $\pm 5 \%$ accuracy); and Multi-Thermo Digital Instruments (with resolution of $0.1{ }^{\circ} \mathrm{C}$ and accuracy of $+/-1^{\circ} \mathrm{C}$ ). In the respective representative sampled houses within the 12 neighborhoods where measurements were taken, the weather stations sensors were positioned at a mounting height of $1.25 \mathrm{~m}$ above ground level and fitted to a sheltered wall to avoid direct sunshine and precipitation.

Table 1. The ASHRAE Scale of warmth

\begin{tabular}{|c|c|}
\hline THERMAL RESPONSE & NUMBERING \\
\hline Hot & +3 \\
\hline Warm & +2 \\
\hline Slightly warm & +1 \\
\hline Neutral & 0 \\
\hline Slightly cool & -1 \\
\hline Cool & -2 \\
\hline Cold & -3 \\
\hline
\end{tabular}




\section{Macrothink}

The survey was done in April which was analyzed to be one of the hottest months in the study area. The survey sites could not be visited simultaneously for respondents to fill their questionnaires because of logistic limitations. Different sets of three survey sites were taken simultaneously in different rounds of the survey across the twelve neighborhoods within the month. For each survey site therefore, data was taken on two days in the month and the maximum, minimum and average values were obtained from the sets of readings. The measurements were taken on sunny days (with bright sunshine, with clear sky and without precipitation) in the month and additional measurements were taken for each location on other days in the same month to verify the data. Along with the measurements of the environmental parameters, the different entities of personal, spatial, location and adaptive factors relevant to thermal comfort were recorded to have a comprehensive assessment of the adaptive thermal response of the residents.

\section{Results}

A total number of 528 respondents were surveyed in Ibadan metropolis. Out of this number, 271 were male $(51.3 \%)$ and 257 were female (48.7\%). 42.8\% of the respondents' were of age 18-30 years, $45.6 \%$ were $31-54$ years and $11.6 \%$ were 55 years and above. With respect to their length of stay in their respective houses, $18 \%$ had stayed for 1-2 years, $54.7 \%$ had stayed for 3-10 years and $27.3 \%$ had stayed for over 10 years. Their value judgments were reliable.

\subsection{Variation of Mean Comfort Vote with Air Temperature}

The pattern of variation of the Mean Comfort Votes of the adaptive thermal responses with indoor and outdoor air temperatures were of interest in this study. According to Humphreys (1975), in most of the studies of thermal comfort a far greater part of the variation in response can be attributed to change in temperature than to changes in either humidity or air movement. A table indicating the various indoor and outdoor temperatures and the calculated mean comfort votes of adaptive thermal response was prepared (Table 2). The percentage of respondents that were in comfort zone was calculated for each case. The Percentage in Comfort 1 consisted of all votes in 'slightly cool', 'neutral' and 'slightly warm' categories. The Percentage in Comfort 2, regarded as better suited for the warm-humid climate, however consisted of all respondents' votes in the 'cool', 'slightly cool', 'neutral' and 'slightly warm' categories. The two computations gave a measure of the percentages of respondents satisfied with the respective temperature values. The respective percentages in discomfort, D1 and D2 were the percentages of respondents that were dissatisfied with the corresponding air temperature values. 
Table 2. Mean Comfort Vote and Percentages in comfort and discomfort.

\begin{tabular}{|l|l|l|l|l|l|l|}
\hline Outdoor Temp. & Indoor Temp. & Mean Vote & \% in Comfort 1 & \%D1 & \% in Comfort 2 & \%D2 \\
\hline 28.0 & 29.5 & -1.920 & 20.54 & 79.46 & 83.93 & 16.07 \\
\hline 28.9 & 30.5 & -1.477 & 46.59 & 53.41 & 87.50 & 12.50 \\
\hline 30.0 & 31.8 & -0.847 & 63.93 & 36.07 & 91.26 & 8.74 \\
\hline 30.5 & 31.5 & -1.437 & 41.67 & 58.33 & 87.50 & 12.50 \\
\hline 30.0 & 30.7 & -1.415 & 40.24 & 59.76 & 87.80 & 12.20 \\
\hline 33.9 & 32.3 & -0.250 & 55.36 & 44.64 & 79.46 & 20.54 \\
\hline 35.8 & 34.0 & 0.941 & 52.94 & 47.06 & 58.09 & 41.91 \\
\hline 36.0 & 34.2 & 1.634 & 33.87 & 66.13 & 36.02 & 63.98 \\
\hline 35.6 & 33.1 & 0.463 & 67.07 & 32.93 & 78.05 & 21.95 \\
\hline 32.0 & 32.2 & -1.070 & 50.89 & 49.11 & 87.50 & 12.50 \\
\hline 32.5 & 31.7 & 0.159 & 70.45 & 29.55 & 82.95 & 17.05 \\
\hline 33.4 & 33.8 & 1.087 & 43.71 & 56.29 & 50.82 & 49.18 \\
\hline 32.7 & 33.3 & 0.054 & 47.69 & 52.31 & 73.08 & 26.92 \\
\hline 27.7 & 30.5 & -1.795 & 15.18 & 84.82 & 74.11 & 25.89 \\
\hline 29.2 & 30.2 & -0.704 & 52.27 & 47.73 & 81.82 & 18.18 \\
\hline 30.2 & 31.2 & -0.302 & 59.89 & 40.11 & 72.53 & 27.47 \\
\hline 28.2 & 31.1 & -0.333 & 50.00 & 50.00 & 85.42 & 14.58 \\
\hline 27.6 & 30.1 & -1.134 & 50.00 & 50.00 & 82.93 & 17.07 \\
\hline
\end{tabular}

Graphs were plotted to relate indoor temperature and mean comfort vote as well as outdoor temperature and mean comfort vote. The graphs indicated significant linear relationships with high R Square values. The data from the table was analyzed to produce the graph (Fig. 2) with the equation relating mean comfort vote to indoor temperature given as:

$$
y=0.627 x-20.38
$$

where $\mathrm{y}=$ mean comfort vote and $\mathrm{x}=$ indoor temperature. $\mathrm{R}$ Square value was 0.762 which implied a very strong linear relationship. The second graph for the outdoor temperature (Fig. 3) also indicated a linear equation as follows:

$$
\mathrm{y}=0.303 \mathrm{x}-9.938
$$

where $\mathrm{y}=$ mean comfort vote and $\mathrm{x}=$ outdoor temperature. $\mathrm{R}$ Square value was 0.700 which implied a very strong relationship.

These equations can be used to provide estimated corresponding values of mean votes of respondents and the indoor and outdoor temperatures. 


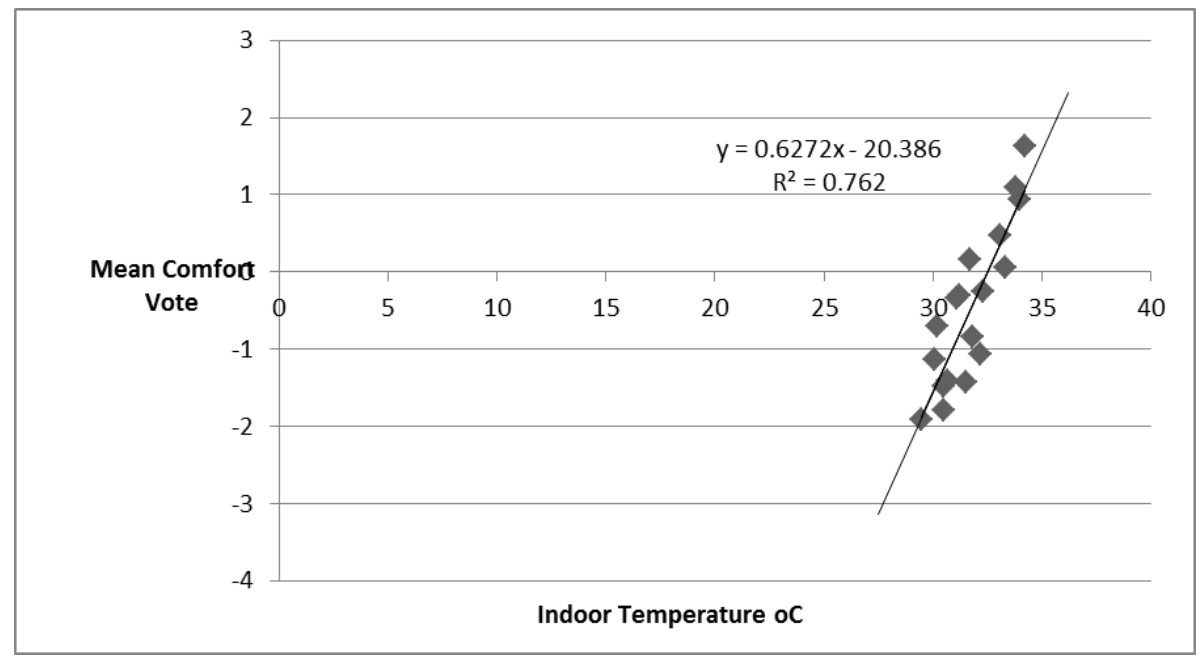

Figure 2. Graph relating Mean Comfort Vote of residents and Indoor Temperature in Ibadan in April 2010

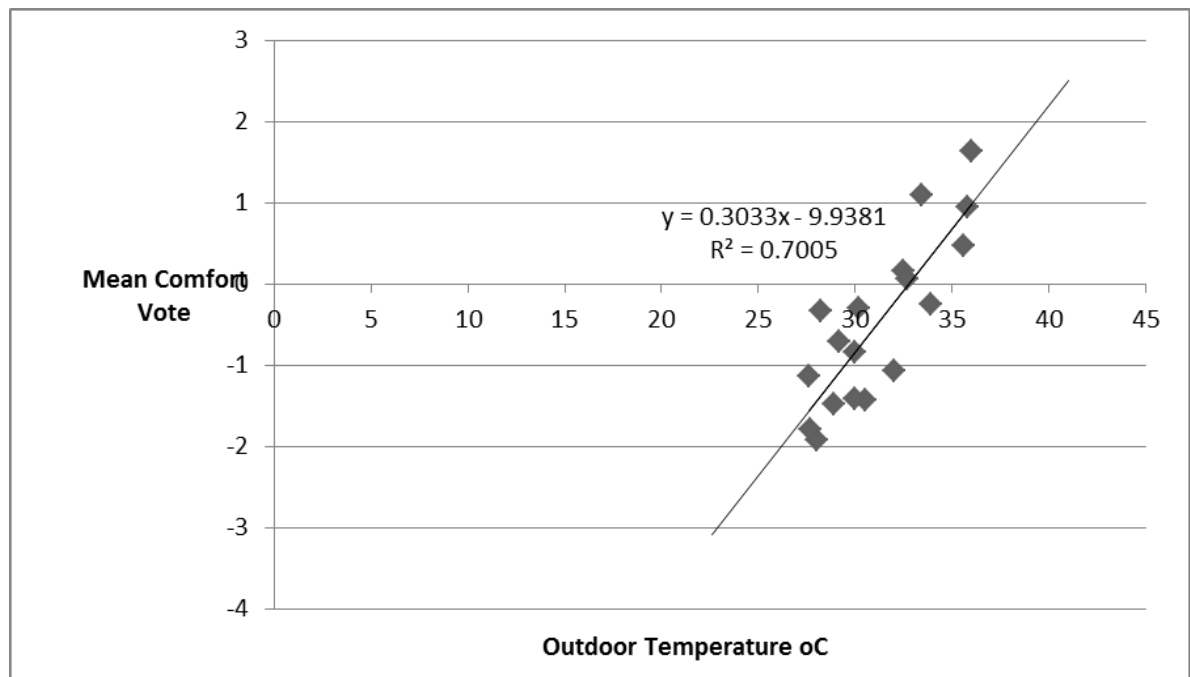

Figure 3. Graph relating Mean Comfort Vote of residents and Outdoor Temperature in Ibadan in April 2010.

The data collected for all other variables were analyzed. All the sets of predictor variables explained remarkable percentages of the variance of the adaptive thermal response in the afternoon period as follows: building spatial characteristics- $35.7 \%(F=14.797, \rho \leq 0.05)$, location characteristics- $26.8 \%(\mathrm{~F}=31.710, \rho \leq 0.05)$, outdoor climatic factors $21.2 \%(\mathrm{~F}=$ $34.382, \rho \leq 0.05)$, personal characteristics- 20.4\% $(\mathrm{F}=10.093, \rho \leq 0.05)$, adaptive actions$14.6 \%(F=5.810, \rho \leq 0.05)$, indoor climatic factors $11.8 \%(F=22.866, \rho \leq 0.05)$. The set of a combination of all the listed variables - personal, adaptive action, climatic, spatial and location characteristics as predictor variables explained $52.1 \%$ of the variance of the adaptive thermal response $(\mathrm{F}=10.474, \rho \leq 0.05)$.

\subsection{Determination of Neutrality Temperature and Optimum Temperature}

As stated earlier, the neutrality temperature also called thermal neutrality is the optimum 
temperature when people feel neither warm nor cool but neutral (Humphreys 1976). To optimize thermal comfort inside a naturally ventilated room, the interior temperature should be maintained at or close to the neutrality temperature. Using the data in the table, the graphs for the percentage of respondents in comfort in relation to indoor temperature gave polynomial curves with the equations as follows:

$$
y=-4.503 x^{2}+290.6 x-4631
$$

where $\mathrm{y}=\%$ in comfort 1 and $\mathrm{x}=$ indoor temperature, $(\mathrm{R}$ Square $=0.405)$. This $\%$ in comfort 1 is the percentage of respondents voting any of these comfort zone categories: slightly cool, neutral and slightly warm.

The graph for the percentage in comfort 2 was also a polynomial curve with equation as follows:

$$
y=-4.208 x^{2}+261.8 x-3987
$$

where $\mathrm{y}=\%$ in comfort 2 and $\mathrm{x}=$ indoor temperature, $(\mathrm{R}$ Square $=0.786)$. This $\%$ in comfort 2 is the percentage of respondents voting in the comfort zone 2 defined to comprise of these four categories: cool, slightly cool, neutral and slightly warm.

The curve of the first graph of $\%$ in comfort 1 had a peak value of 58\% in comfort at indoor temperature value of $32.2^{\circ} \mathrm{C}$ (Figure 4). According to Humphreys (1975), the peak value of the $\%$ in comfort 1 curve would correspond to the value of the neutrality temperature. The neutrality temperature is the temperature at which the maximum number of people feels neither hot nor cold. It is regarded as the mid-point of the comfort zone. Therefore, by this convention the value for the neutrality temperature for the respondents in this study was determined to be $32.2^{\circ} \mathrm{C}$ from the first $\%$ in comfort 1 graph. It was however not acceptable that the percentage in comfort was only $58 \%$ and not anywhere near to the required optimum temperature value of $95 \%$ in comfort so that only $5 \%$ would be dissatisfied. The acceptable neutrality temperature would therefore be ideally lower than $32.2^{\circ} \mathrm{C}$ to obtain a greater percentage in comfort.

Taking the curve of the second graph of $\%$ in comfort 2 , the peak value was $87 \%$ and corresponding temperature was $30.7^{\circ} \mathrm{C}$ (Figure 5). This value of $30.7^{\circ} \mathrm{C}$ could be more acceptable as the optimum neutrality temperature for the respondents since it had the highest percentage in comfort value of $87 \%$. The comfort zone 2 which included cool category was utilized since majority of respondents $(79.9 \%)$ preferred to feel cooler during the survey. It was deduced that their preferred temperature and hence optimum temperature could only be adequately determined within a comfort zone that included the cool category. Also, according to Hwang et al (2009), the comfort limits corresponding to $80 \%$ acceptability for hot-humid region was found to be -1.45 (cool) and +0.65 (slightly warm) rather than -0.85 and +0.85 suggested by ISO 7730. The study found that the inclusion of the cool category in the comfort zone for the hot-humid and other tropical climates was necessary for comfort standards analysis. The $\%$ in comfort 2 was therefore considered to provide a better analysis of the indoor comfort situation than the $\%$ in comfort 1 in this study. The temperature value of $30.7^{\circ} \mathrm{C}$ at which $87 \%$ of the respondents were in comfort obtained from the $\%$ in comfort 2 
graph was therefore determined as the optimum neutrality temperature. It was preferred to the conventionally obtained value of $32.2^{\circ} \mathrm{C}$ which only accounted for $58 \%$ in comfort. The actual value of acceptable comfort temperature corresponding to $95 \%$ in comfort could not be obtained since $95 \%$ of respondents were not found in comfort within the contextual range of this survey. The value of $30.7^{\circ} \mathrm{C}$ could however be taken as an approximate value with respect to the range of indoor thermal conditions experienced by respondents in this study.

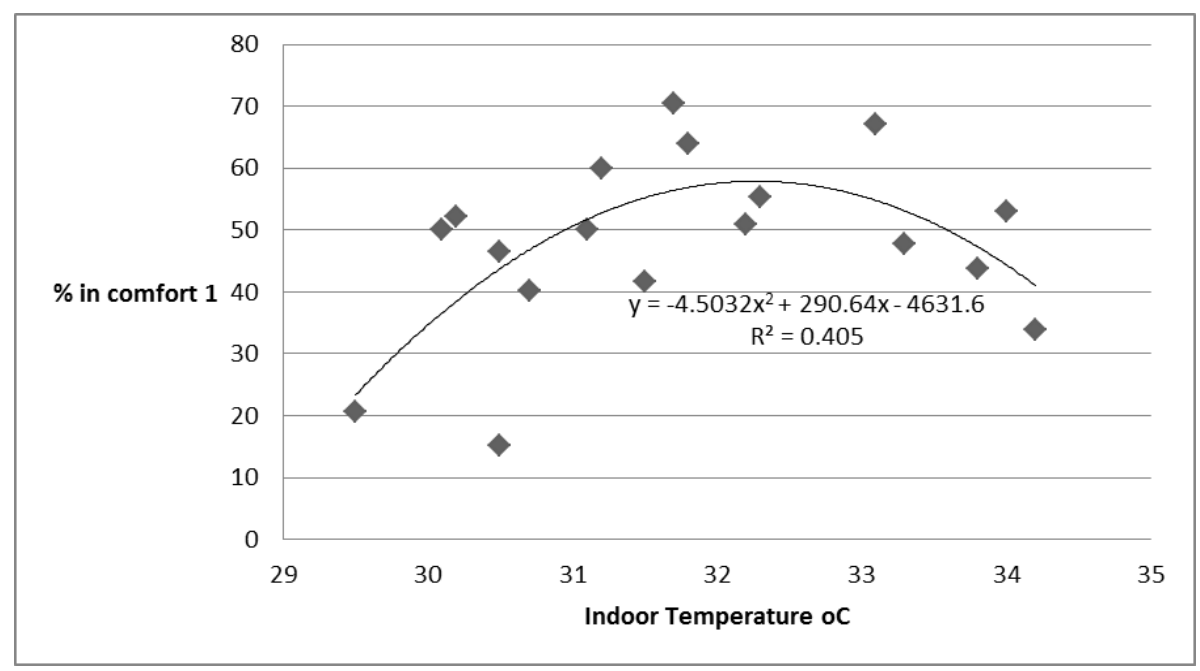

Figure 4. Graph of Percentage in comfort 1 in relation to Indoor temperature for Ibadan in April 2010 with equation

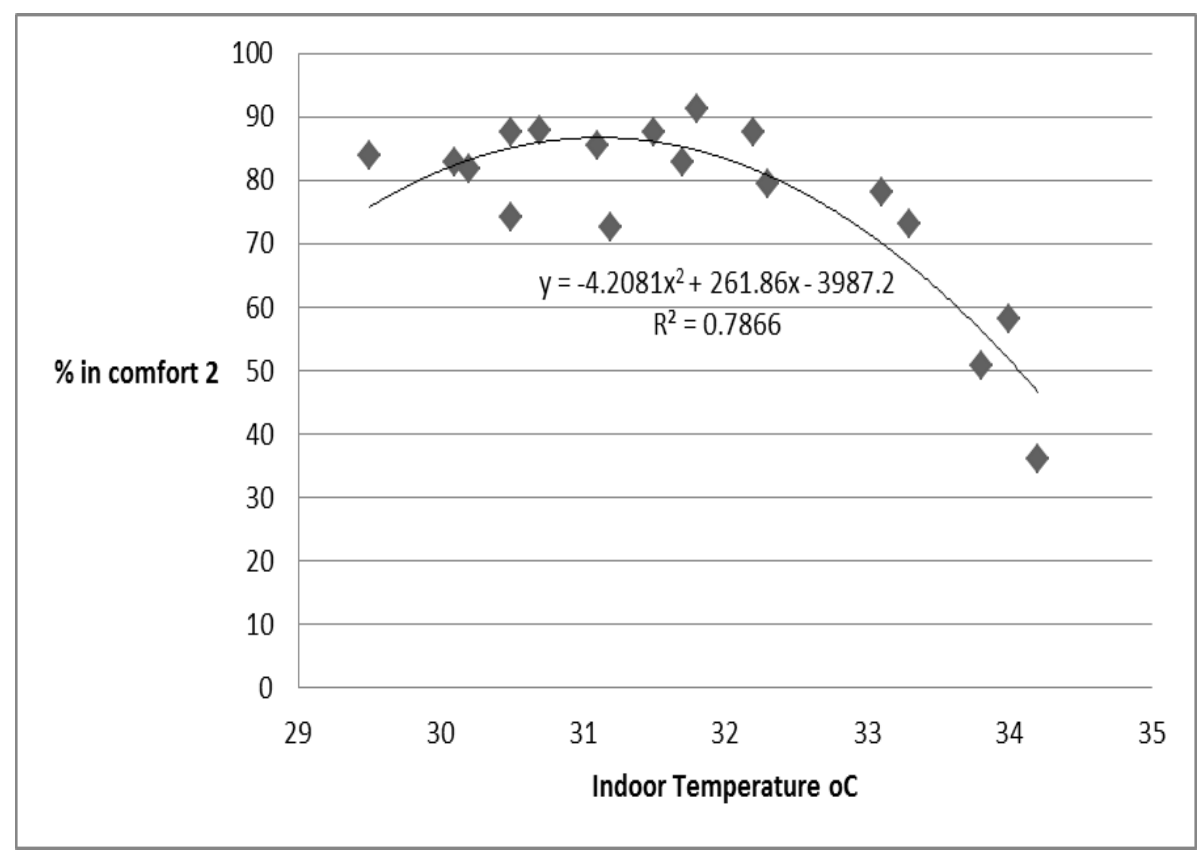

Figure 5. Graph of Percentage in comfort 2 in relation to Indoor temperature for Ibadan in April 2010 with equation

The equations given in previous works for obtaining neutrality temperature $T_{n}$ were applied to determine which could be applicable to the findings in this study. According to Humphreys 
(1978), $\mathrm{T}_{\mathrm{n}}=11.9+0.534 \mathrm{~T}_{\text {oav }}$ where $\mathrm{T}_{\mathrm{oav}}$ is the month's mean outdoor temperature. Using this equation and taking $\mathrm{T}_{\text {oav }}=28^{\circ} \mathrm{C}, \mathrm{T}_{\mathrm{n}}$ was found to be $26.85^{\circ} \mathrm{C}$. Auliciems (1981) gave the equation $\mathrm{T}_{\mathrm{n}}=17.6+0.31 \mathrm{~T}_{\text {oav }}$. Using this equation and taking $\mathrm{T}_{\text {oav }}=28^{\circ} \mathrm{C}, \mathrm{T}_{\mathrm{n}}=26.28^{\circ} \mathrm{C}$. Using Griffiths (1990) equation, $\mathrm{T}_{\mathrm{n}}=12.1+0.534 \mathrm{~T}_{\text {oav }}, \mathrm{T}_{\mathrm{n}}$ was found to be $27.05^{\circ} \mathrm{C}$. With Nicol and Roaf (1996) equation: $\mathrm{T}_{\mathrm{n}}=17+0.38 \mathrm{~T}_{\mathrm{oav}}, \mathrm{T}_{\mathrm{n}}$ was found to be $27.64^{\circ} \mathrm{C}$. Using deDear et al (1997) equation, $\mathrm{T}_{\mathrm{n}}=17.8+0.31 \mathrm{~T}_{\text {oav }}$, gave $\mathrm{T}_{\mathrm{n}}=26.48^{\circ} \mathrm{C}$.

\section{Discussion}

It must be noted that there were several other factors in the study that influenced the mean vote along with air temperature. The data collected for all other variables were analyzed. . From the regression analyses, the five categorized sets of factors (personal, adaptive action, climatic, building spatial and location characteristics) were relevant to the determination of the indoor thermal comfort of the respondents. All the sets of predictor variables explained remarkable percentages of the variance of the adaptive thermal response in the afternoon period as follows: building spatial characteristics- 35.7\% $(F=14.797, \rho \leq 0.05)$, location characteristics- $26.8 \%(\mathrm{~F}=31.710, \rho \leq 0.05)$, outdoor climatic factors $21.2 \%(\mathrm{~F}=34.382$, $\rho \leq 0.05)$, personal characteristics- $20.4 \%(\mathrm{~F}=10.093, \rho \leq 0.05)$, adaptive actions- $14.6 \%(\mathrm{~F}=$ $5.810, \rho \leq 0.05)$, indoor climatic factors $11.8 \%(F=22.866, \rho \leq 0.05)$. The set of a combination of all the listed variables - personal, adaptive action, climatic, spatial and location characteristics as predictor variables explained $52.1 \%$ of the variance of the adaptive thermal response $(F=10.474, \rho \leq 0.05)$. When interpreting the respective results obtained for indoor temperature from equation (1) and outdoor temperatures from equation (2) therefore, the substantial contextual input of other variables of adaptive thermal comfort especially adaptive actions must be recognized. It was deduced that the respondent's adaptive actions enabled them to tolerate the high values of indoor and outdoor temperatures recorded in the study. The uncomfortable thermal conditions in the periods of discomfort provided the basis for the principle of adaptive comfort to be operational. The adaptive principle states that if a change occurs such as to produce discomfort, people react in ways which tend to restore their comfort (Nicol and Humphreys 2002).

It can be inferred that there is essentially a climatic and contextual basis for the application of thermal neutrality equations. From the results, the nearest predicted value of thermal neutrality $T_{n}$ to the $30.7^{\circ} \mathrm{C}$ obtained in this study was the $T_{n}$ from Nicol and Roaf (1996) equation: $27.64^{\circ} \mathrm{C}\left(\mathrm{T}_{\mathrm{n}}=17+0.38 \mathrm{~T}_{\text {oav }}\right)$ which was less by as much as $3.06 \mathrm{deg} \mathrm{C}$. It should be noted that all calculated $\mathrm{T}_{\mathrm{n}}$ values were less than the obtained value of $30.7^{\circ} \mathrm{C}$. The obtained $\mathrm{T}_{\mathrm{n}}$ in this study was therefore higher than the values predicted by these models. This indicated that the respondents tolerated higher temperatures by $3.06 \mathrm{deg} \mathrm{C}$ above the predictions from the examined Nicol and Roaf $\mathrm{T}_{\mathrm{n}}$ equation, $3.65 \mathrm{deg} \mathrm{C}$ above Griffith's equation, 3.85 deg $\mathrm{C}$ above Humphreys' equation, 4.22 deg $\mathrm{C}$ above deDear's equation and $4.42 \mathrm{deg} \mathrm{C}$ above Auliciems' equation. This confirmed the effect of the respondents' adaptive actions and the result therefore validates the adaptive principle. The adaptive nature of thermal comfort has been expressed as being a means of extending the comfort conditions within spaces as occupants utilize the adaptive opportunities available to them (Humphreys and Nicol 2000,2002, Nicol and Humphreys 2002, Merghani 2004, Boerstra 2006). Adaptive 
thermal comfort has been shown through several findings to be the actual experience of people within the thermal environment created in spaces within and around built structures.

The difference of the field result compared to predictions of models has implications with regard to the stipulation of building comfort standards. It is inferred that the more realistic thermal neutrality can better be determined by the contextual field study approach. Additionally, more energy can be saved through architectural design utilizing the adaptive comfort approach of providing ample adaptive opportunity. This needs to be emphasized due to the significant impact of building spatial characteristics on adaptive thermal comfort of the residents in this study. This has also especially been demonstrated through the use of adaptive opportunity by building occupants as reported in literature. Spatial diversity has been found to be of interest in the determination of adaptive thermal comfort (Baker and Standeven 1996, Merghani 2004). Through the various inferences from previous studies, both environmental and spatial diversity can be conceptualized as adaptive opportunities and need to be taken as building design factors to make buildings occupants benefit more from the adaptive principle and culminating in sustainable comfort.

\section{Conclusion}

From the above findings it could be inferred that the differentials of the tropical warm-humid climatic conditions of the study area and the contextual urban residential environment as well as the adaptive actions of the respondents had necessitated a requirement for adjustment to the applicability of the thermal neutrality equations in the study area. The respondents in this study have utilized the adaptive opportunity available to them and could therefore extend their comfort zone to higher temperatures than the predicted comfort temperatures and comfort standards. It was found that the residents' thermal neutrality was higher than values predicted by the applied equations thereby indicating opportunity for sustainable comfort. Hence, the applicability of the thermal neutrality equations in a tropical warm-humid urban condition needs further modifications because of its peculiar climatic context. Essentially, there should be a climatic and contextual basis for the application of the thermal neutrality equations.

\section{Acknowledgement}

The author acknowledges the support granted for the publication by the Global Excellence and Stature (GES) Postdoctoral Fellowship and the Faculty of Art, Design and Architecture of the University of Johannesburg, South Africa.

\section{References}

Absolute Astronomy (n.d.) Analysis of Ibadan climate [Online] Available: http://www.absoluteastronomy.com/topics/Ibadan (August 15, 2011)

Asiyanbola, R. A. (2011). Gender and urban housing settings in Africa-Nigeria. (Paper presented at the International RC21 Conference on The struggle to belong- Dealing with diversity in $21^{\text {st }}$ century urban settings. Amsterdam, July 2011). [Online] Available: http://www.rc21.org/conferences/amsterdam2011/edocs/ (September 8, 2011) 
Auliciems, A. (1981). Toward a psycho-physiological model of thermal perception. International Journal of Biometeorology, 25(2), 109-122.

https://doi.org/10.1007/BF02184458

Auliciems, A. (1982). Psych-physiological criteria for global thermal zones. International Journal of Biometeorology, 26, 69-86.

Baker, N. V., \& Standeven, M. A. (1994). Comfort criteria for passively cooled buildings: A PASCOOL task. Renewable Energy, 5(5), 977-984.

https://doi.org/10.1016/0960-1481(94)90120-1

Boerstra, A. (2006). The adaptive thermal comfort criterion in the new EPBD IEQ standard. In Proceedings Conference on Comfort and Energy Use in Buildings-Getting it right. Windsor Great Park, U.K. 27-30 April 2006 NCEUB. http://www.nceub.org.uk/

De Dear, R. (1998). A global database for thermal comfort field experiments. ASHRAE Transactions, 104(1b), 1141-1152.

De Dear, R., Brager, G. S., \& Cooper, D. (1997). Developing an adaptive model of thermal comfort and preference: Final Report on ASHRAE RP-884. Macquarie University, Sydney.

Fanger, P. O. (1970). Thermal comfort. Copenhagen: Danish Technical Press.

Fanger, P. O. (1973). Thermal Comfort, analysis and applications in environmental engineering. New York: McGraw-Hill.

Givoni, B. (1976). Man, Climate and Architecture. Barking,Essex: Applied Science Publishers.

Givoni, B. (1998): Climate considerations in building and urban design. John Wiley, UK.

Griffiths, I. (1990). Thermal comfort studies in buildings with passive solar features: field studies. Report to CEC. ENS35 090, UK

Haase, M., \& Amato, A. (2009). An investigation of the potential for natural ventilation and building orientation to achieve thermal comfort in warm and humid climates. Solar Energy, 83(3), 389-399. http://dx.doi.org/10.1016/j.solener.2008.08.015

Humphreys, M. A. (1976). Field studies of thermal comfort compared and applied. Build Services Eng, 44, 5-27.

Humphreys, M. A. (1978). Outdoor temperatures and comfort indoors. Build Res and Pract (J of $C I B), 6(2), 92-105$. https://doi.org/10.1080/09613217808550656

Humphreys, M. A., \& Nicol, J. F (2002). The Validity of ISO-PMV for predicting comfort votes in everyday thermal environments. Energy and Building, 34(6), 667-684.

https://doi.org/10.1016/S0378-7788(02)00018-X

Humphreys, M. A., Nicol, J. F., \& Raja, I. A. (2007), Field studies of indoor thermal comfort and progress of the adaptive approach In Santamouris, M. (ed) Advances in Building Energy 
Research 1 Earthscan 55-88. https://doi.org/10.1080/17512549.2007.9687269

Hwang, R., Cheng, M., Lin, T., \& Ho, M. (2009). Thermal perception, general adaptation methods and occupant's idea about the trade-off between thermal comfort and energy saving in hot-humid regions. Building and Environment, 44(6), 1128-1134.

http://dx.doi.org/10.1016/j.buildenv.2008.08.001

ISO (International Organization for Standardization) (1984) Moderate thermal environments: determination of the PMV and PPD indices and specification of the conditions for thermal comfort, ISO 7730. Geneva, International Organization for Standardization

Mallick, F. H. (1996). Thermal comfort and building design in the tropical climates. Energy and Building, 23(3), 161-167. http://dx.doi.org/10.1016/0378-7788(95)00940-X

Markus, T. A., \& Morris, E. N. (1980). Building, climate and energy. London: Pitman.

McIntyre, D. A. (1980). Indoor Climate. Barking,Essex: Applied Science Publishers.

Merghani, A. (2004) Exploring thermal comfort and spatial diversity In Steemers, K.,

Steane, M. A. (eds), Environmental Diversity in Architecture. Spon press, NY, USA, London, UK 195-214

NBS (National Bureau of Statistics) (2008) Annual abstract of statistics 2008. NBS, Nigeria

Nicol, J. F., \& Humphreys, M. A. (2002). Adaptive thermal comfort and sustainable thermal standards for buildings. Energy and Building, 34(6), 563-572.

http://dx.doi.org/10.1016/S0378-7788(02)00006-3

Nicol, J. F., \& Humphreys, M. A. (2010). Derivation of the adaptive equations for thermal comfort in free-running buildings in European standard EN 15251. Building and Environment, 45(1),11-17. http://dx.doi.org/10.1016/j.buildenv.2008.12.013

Nicol, J. F., \& Roaf, S. (1996). Pioneering new indoor temperature standards: the Pakistan project. Energy and Building, 23(1), 169-174. https://doi.org/10.1016/0378-7788(95)00941-8

Ogunsote, O. O., \& Prucnal-Ogunsote, B. (2002). Defining climatic zones for architectural design in Nigeria: a systematic delineation. Journal of Environmental Technology, 1(2), 1-14

Ojo, O. (1977). The climates of West Africa. London: Heinemann Educational Books.

Peeters, L., De Dear, R., Hensen, J., \& D'haeseleer, W. (2009). Thermal comfort in residential buildings: comfort values and scales for building energy simulation. Applied Energy, 86(5), 772-780. http://dx.doi.org/10.1016/j.apenergy.2008.07.011

Santamouris, M. (2006). Adaptive thermal comfort and ventilation. A.I.V.C. Ventilation Information Paper, AIVC VIP 12. http://www.aivc.org/

Sharma, M. R., \& Ali, S. (1986). Tropical summer index- a study of thermal comfort in Indian subjects. Building and Environment, 21(1), 11-24. I

https://doi.org/10.1016/0360-1323(86)90004-1 


\section{Macrothink}

Environmental Management and Sustainable Development

ISSN 2164-7682

2016, Vol. 5, No. 2

Wikipedia (n.d.). Ibadan climate- BBC Weather analysis chart [Online] Available: http://en.wikipedia.org/wiki/Ibadan,Nigeria\#\# (April 10, 2010).

\section{Copyright Disclaimer}

Copyright for this article is retained by the author(s), with first publication rights granted to the journal.

This is an open-access article distributed under the terms and conditions of the Creative Commons Attribution license (http://creativecommons.org/licenses/by/3.0/). 